ARTICLE

\title{
Crystallization-induced mechanofluorescence for visualization of polymer crystallization
}

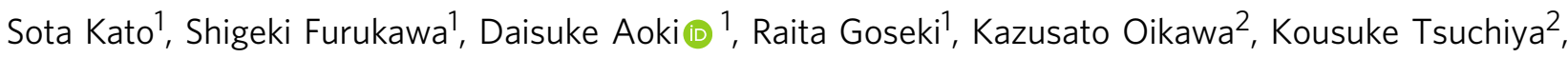
Naohiko Shimada ${ }^{3}$, Atsushi Maruyama ${ }^{3}$, Keiji Numata (i) ${ }^{2}$ \& Hideyuki Otsuka (i) ${ }^{1 \times}$

The growth of lamellar crystals has been studied in particular for spherulites in polymeric materials. Even though such spherulitic structures and their growth are of crucial importance for the mechanical and optical properties of the resulting polymeric materials, several issues regarding the residual stress remain unresolved in the wider context of crystal growth. To gain further insight into micro-mechanical forces during the crystallization process of lamellar crystals in polymeric materials, herein, we introduce tetraarylsuccinonitrile (TASN), which generates relatively stable radicals with yellow fluorescence upon homolytic cleavage at the central $\mathrm{C}-\mathrm{C}$ bond in response to mechanical stress, into crystalline polymers. The obtained crystalline polymers with TASN at the center of the polymer chain allow not only to visualize the stress arising from micro-mechanical forces during polymer crystallization via fluorescence microscopy but also to evaluate the micro-mechanical forces upon growing polymer lamellar crystals by electron paramagnetic resonance, which is able to detect the radicals generated during polymer crystallization.

\footnotetext{
${ }^{1}$ Department of Chemical Science and Engineering, Tokyo Institute of Technology, 2-12-1 Ookayama, Meguro-ku, Tokyo 152-8550, Japan.

2 Biomacromolecules Research Team, RIKEN Center for Sustainable Resource Science, 2-1 Hirosawa, Wako, Saitama 351-0198, Japan. ${ }^{3}$ School of Life Science and Technology, Tokyo Institute of Technology, 4259 Nagatsuta-cho, Midori-ku, Yokohama, Kanagawa 226-8501, Japan. ${ }^{\circledR e m a i l: ~ o t s u k a @ m a c . t i t e c h . a c . j p ~}$
} 
C rystalline polymers such as polyethylene and polyethylene terephthalate are indispensable for our daily lives. Their mechanical and optical properties strongly depend on their crystallinity ${ }^{1}$, which in turn is closely correlated to molding parameters. The crystallization of such synthetic polymers has been extensively studied, especially from a morphological and kinetic perspective ${ }^{2}$. Unlike amorphous resins, crystalline polymers experience stress at freezing and contain residual stress due to crystallization. However, the micro-mechanical forces during polymer crystallization remains an intensely debated topic, since suitable techniques to quantitatively evaluate this phenomenon have not yet been established. So far, only theoretical, indirect-experimental, or empirical discussions have been employed. In order to avoid material failure due to micro-mechanical forces during polymer crystallization, researchers and manufacturers have employed various experimental techniques. The approaches to assess the magnitude of micro-mechanical forces during polymer crystallization in polymer components can be classified into three distinct categories: Non-destructive ${ }^{3}$, destructive ${ }^{4}$, and predictive ${ }^{5}$. Among these, non-destructive methods such as holographic interferometry and synchrotron X-ray diffraction analysis have been used to visualize the physical relaxation of components during heating and to calculate their initial stress state. Despite the fact that the non-destructive nature of these methods is without doubt an advantage, they have been unable to accomplish neither a qualitative evaluation nor stress visualization in real time. From the viewpoint of the molecular topology of the amorphous phase, micro-mechanical forces during polymer crystallization in tie chain segments, which are molecular connections between individual crystallites, have been yet an important issue for the tensile or compression behavior of semicrystalline polymers, the fracture toughness, and the resistance to slow crack growth ${ }^{6,7}$. Topological features such as tie chain segments and loop segments, and the alternation of crystalline and amorphous domains have formed the basis of most molecular-level description of the semicrystalline state ${ }^{8,9}$.

On the other hand, various types of mechano-functional polymers have recently been developed based on mechanoresponsive molecules called mechanophores ${ }^{10-12}$, which are activated in response to mechanical stress arising from exposure to ultrasonic ${ }^{13-16}$, stretching ${ }^{17-19}$, compression ${ }^{20}$, swelling ${ }^{21}$, or solvent-coagulation forces $22-25$. Our group has been developing radical-type mechanochromophores that exhibit coloration and fluorescence derived from relatively stable radicals generated upon homolytic cleavage of $\mathrm{C}-\mathrm{C}$ bonds in response to exposure to mechanical stress. For example, a diarylbibenzofuranone ${ }^{22}$ generates blue radicals upon the homolytic cleavage of its central C-C bond, while tetraarylsuccinonitrile (TASN; Fig. 1a) ${ }^{26}$ generates pink radicals that emit yellow fluorescence under UV irradiation.

In the present study, the above-mentioned radical-type mechanochromophores, especially TASN, were introduced into the center of the main chain of crystalline polymers. As TASN at the cross-linking point can be cleaved in response to the solventcoagulation force in freezing cross-linked polymer gels, we hypothesized that TASN in a tie molecule could potentially be mechanically cleaved by the growth of lamellar crystals (henceforth: crystallization-induced mechanofluorescence (CIMF)) (Fig. 1b). Accordingly, the corresponding fluorescence of radicals generated from TASN would enable a visualization of the crystallization. The advantage of using radical-type mechanochromophores lies in the generated radicals, which can be examined by electron paramagnetic resonance (EPR) measurements. Thus, the present system is suitable for the detection of low degrees of stress that arise from micro-mechanical forces during polymer crystallization. Fluorescence microscopy observations of CIMF allows the precise identification of the stress
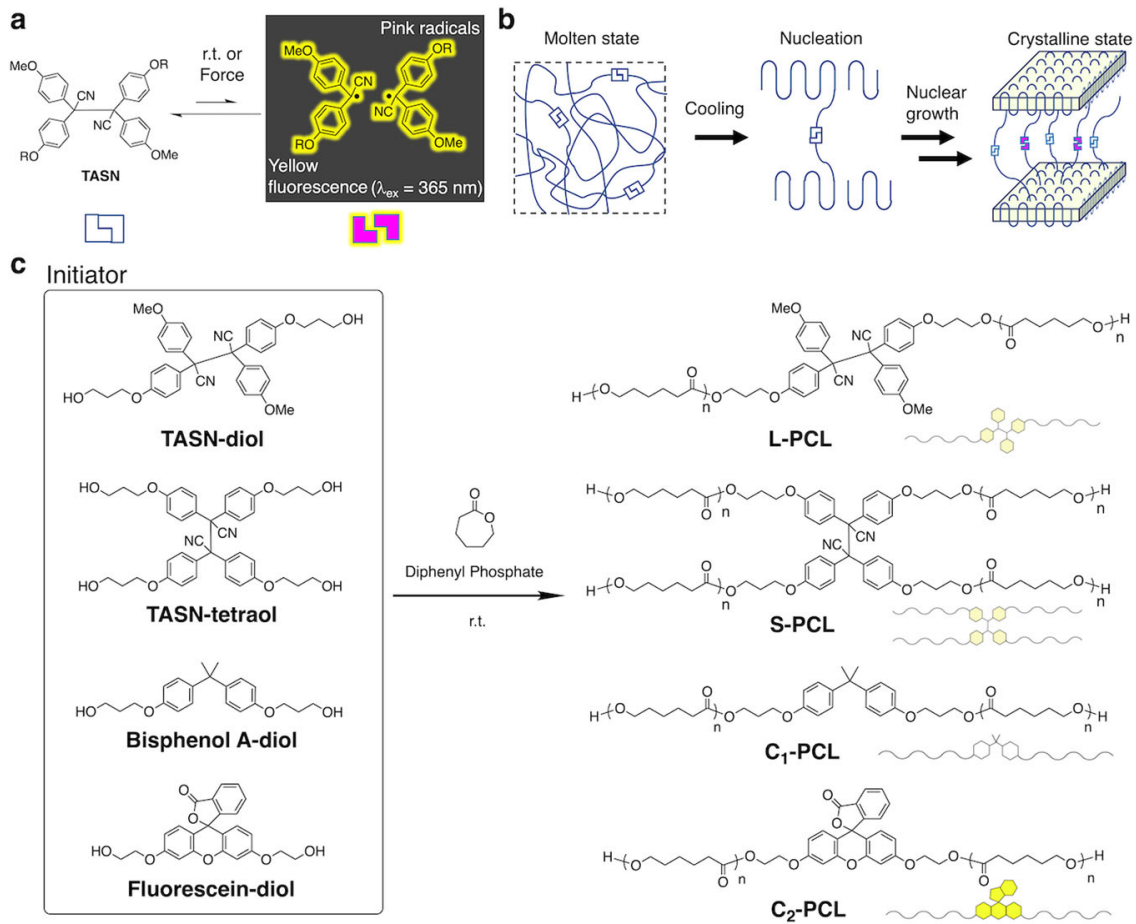

Fig. 1 Conceptual illustration of the TASN moiety as a fluorescent probe and schematic image of CIMF. a Chemical structure of tetraarylsuccinonitrile (TASN) and its equilibrium with the corresponding C-C-cleaved radicals. $\mathbf{b}$ Schematic image of the crystallization of a TASN-centered polymer from its molten state. c Synthetic scheme of TASN-containing linear polycaprolactone (L-PCL), TASN-containing star polycaprolactone (S-PCL), and control polycaprolactones that contain bisphenol $\mathrm{A}\left(\mathbf{C}_{\mathbf{1}}-\mathbf{P C L}\right)$ or fluorescein $\left(\mathbf{C}_{\mathbf{2}}-\mathbf{P C L}\right)$ at the center of the chain. 
location and an in-depth clarification of the polymer crystallization process.

\section{Results}

Strategy and system. In this study, polycaprolactone (PCL) was chosen as the crystalline polymer based on the following three considerations. Firstly, even at room temperature, TASN is in equilibrium with a small amount of dissociated radicals, and it is unstable at temperatures beyond $100^{\circ} \mathrm{C}$. The melting point $\left(\sim 50^{\circ} \mathrm{C}\right)$ and the crystallization temperature $\left(\sim 30^{\circ} \mathrm{C}\right)$ of PCL mean that TASN can be used under relatively mild conditions, which the effect of this paper is limited to PCL melts. Secondly, a series of PCLs can be easily synthesized in one step using the living ring-opening polymerization of $\varepsilon$-caprolactone initiated by TASN derivatives with two (TASN-diol) or four hydroxy groups (TASN-tetraol) as the initiators. Thirdly, PCL has been studied extensively and ample basic data on PCL is available $27-35$.

As shown in Fig. 1c, a series of PCLs were synthesized using (1) TASN-diol, (2) TASN-tetraol, (3) Bisphenol A-diol, and (4) Fluorescein-diol as initiators, in the presence of diphenyl phosphate (DPP) as the bulk catalyst ${ }^{36,37}$. Linear and starshaped PCLs with TASN are henceforth referred to as L-PCL and S-PCL, respectively. Control PCLs prepared from Bisphenol Adiol and Fluorescein-diol are henceforth referred to as $\mathbf{C}_{\mathbf{1}}-\mathbf{P C L}$ and $\mathbf{C}_{\mathbf{2}}-\mathbf{P C L}$, respectively. $\mathbf{C}_{\mathbf{1}} \mathbf{- P C L}$ was synthesized as a control PCL that is not cleaved in response to micro-mechanical forces during polymer crystallization, while $\mathbf{C}_{\mathbf{2}}$-PCL was synthesized as a polymer that continuously emits fluorescence during the formation of spherulites. All PCLs were successfully synthesized and their molecular weight, molecular weight distribution, and thermal properties are summarized in Table 1. PCLs with different molecular weights were successfully synthesized by changing the monomer-to-initiator feed ratio.

CIMF during isothermal crystallization. CIMF was investigated on the series of synthesized PCLs. Initially, the PCL samples were exposed to simple heating. During the heating process (heating rate: $\left.50{ }^{\circ} \mathrm{C} \mathrm{min}^{-1}\right)$, the PCL samples were completely molten at $70^{\circ} \mathrm{C}$, where they were kept for $2 \mathrm{~min}$. Subsequently, the samples were cooled to $30^{\circ} \mathrm{C}$ (cooling rate: $-20^{\circ} \mathrm{C} \mathrm{min}^{-1}$ ), where they were kept for crystallization. During the crystallization, both pink coloration and yellow fluorescence, due to the dissociation of TASN, were observed (Fig. 2a). During the cooling process from $70^{\circ} \mathrm{C}$ to $0{ }^{\circ} \mathrm{C}$, EPR measurements on L-PCL $\left(M_{\mathrm{n}, \mathrm{NMR}}=13,000\right)$ supported the hypothesis that the dissociation of TASN is mainly induced by crystallization and not by melting (Supplementary Fig. 21). Solid-state UV-vis (Fig. 2b) and fluorescence measurements (Fig. $2 \mathrm{c})$ on L-PCL $\left(M_{\mathrm{n}, \mathrm{NMR}}=13,000\right)$ after isothermal crystallization showed an absorption peak at $548 \mathrm{~nm}$ in the UVvis measurement and an emission peak at $560 \mathrm{~nm}$ in the fluorescence measurement. These peaks unambiguously indicate the generation of diarylacetonitrile (DAAN) radicals derived from $\mathrm{TASN}^{26}$. Furthermore, in the solid-state fluorescence measurement, the fluorescence intensity drastically increased upon shifting the excitation wavelength to $548 \mathrm{~nm}$. Therefore, an argon laser $\left(\lambda_{\mathrm{ex}}=514 \mathrm{~nm}\right)$ was chosen for the subsequent fluorescent microscopy observations of PCLs in order to gain clear images of the spherulites.

Table 1 Molecular weight and thermal properties of L-PCL, S-PCL, $C_{1}-P C L$, and $C_{2}-P C L$ Molecular weight and thermal properties of the synthesized linear and star-shaped polycaprolactones that contain a mechanochromophore or a control moiety.

\begin{tabular}{|c|c|c|c|c|c|c|c|}
\hline Structure & [I]:[M] & $M_{n}{ }^{a} / \mathrm{g} \mathrm{mol}^{-1}$ & $M_{\mathrm{n}}^{\mathrm{b}} / \mathrm{g} \mathrm{mol}^{-1}$ & $M_{w} / M_{n}^{b}$ & $T_{m}{ }^{c} /{ }^{\circ} \mathrm{C}$ & $\Delta H_{\mathrm{m}} \mathrm{c} / \mathrm{J} \mathrm{g}^{-1}$ & $X_{c}{ }^{c} / \%$ \\
\hline \multirow[t]{3}{*}{$L-P C L$} & $1: 50$ & 7100 & 9800 & 1.16 & 51 & 59 & 44 \\
\hline & $1: 100$ & 13,000 & 17,500 & 1.19 & 55 & 57 & 42 \\
\hline & $1: 200$ & 24,400 & 24,100 & 1.20 & 55 & 57 & 42 \\
\hline \multirow[t]{2}{*}{ S-PCL } & $1: 100$ & 12,600 & 14,400 & 1.13 & 51 & 54 & 40 \\
\hline & $1: 200$ & 25,200 & 29,500 & 1.14 & 55 & 58 & 43 \\
\hline $\mathrm{C}_{1}-\mathrm{PCL}$ & $1: 100$ & 11,800 & 14,900 & 1.07 & 55 & 60 & 44 \\
\hline $\mathrm{C}_{2}-\mathrm{PCL}$ & $1: 100$ & 8600 & 10,500 & 1.19 & 51 & 61 & 45 \\
\hline \multicolumn{8}{|c|}{ 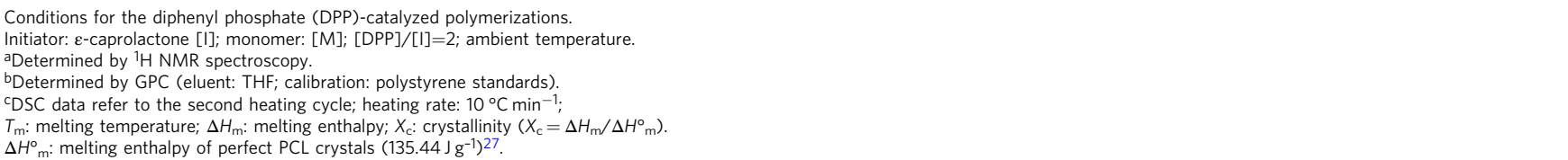 } \\
\hline
\end{tabular}

a

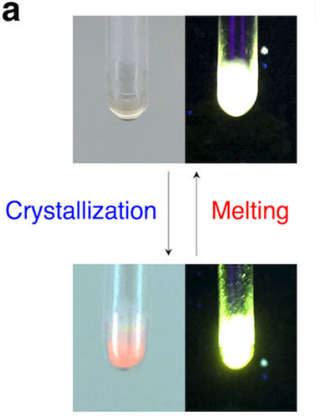

b

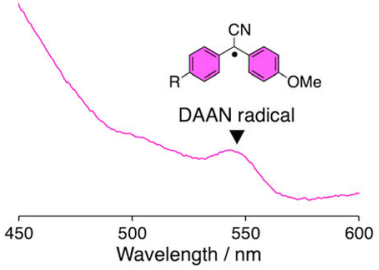

C

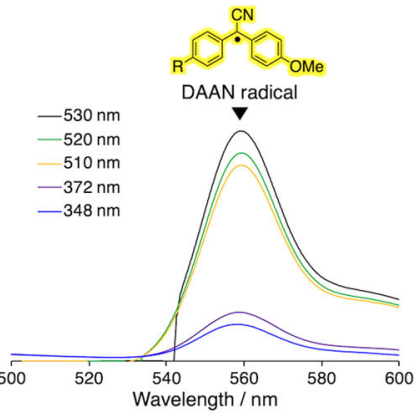

Fig. 2 CIMF during isothermal crystallization. a CIMF of L-PCL $\left(M_{n, N M R}=13000\right)$, which contains a TASN moiety at the center of the main chain. $\mathbf{b}$ Solidstate UV-vis spectrum of L-PCL $\left(M_{n, N M R}=13,000\right)$ after isothermal crystallization. c Solid-state fluorescence spectra of L-PCL $\left(M_{n, N M R}=13,000\right)$ after isothermal crystallization under different excitation wavelength. (DAAN radical: diarylacetonitrile radical derived from TASN). 

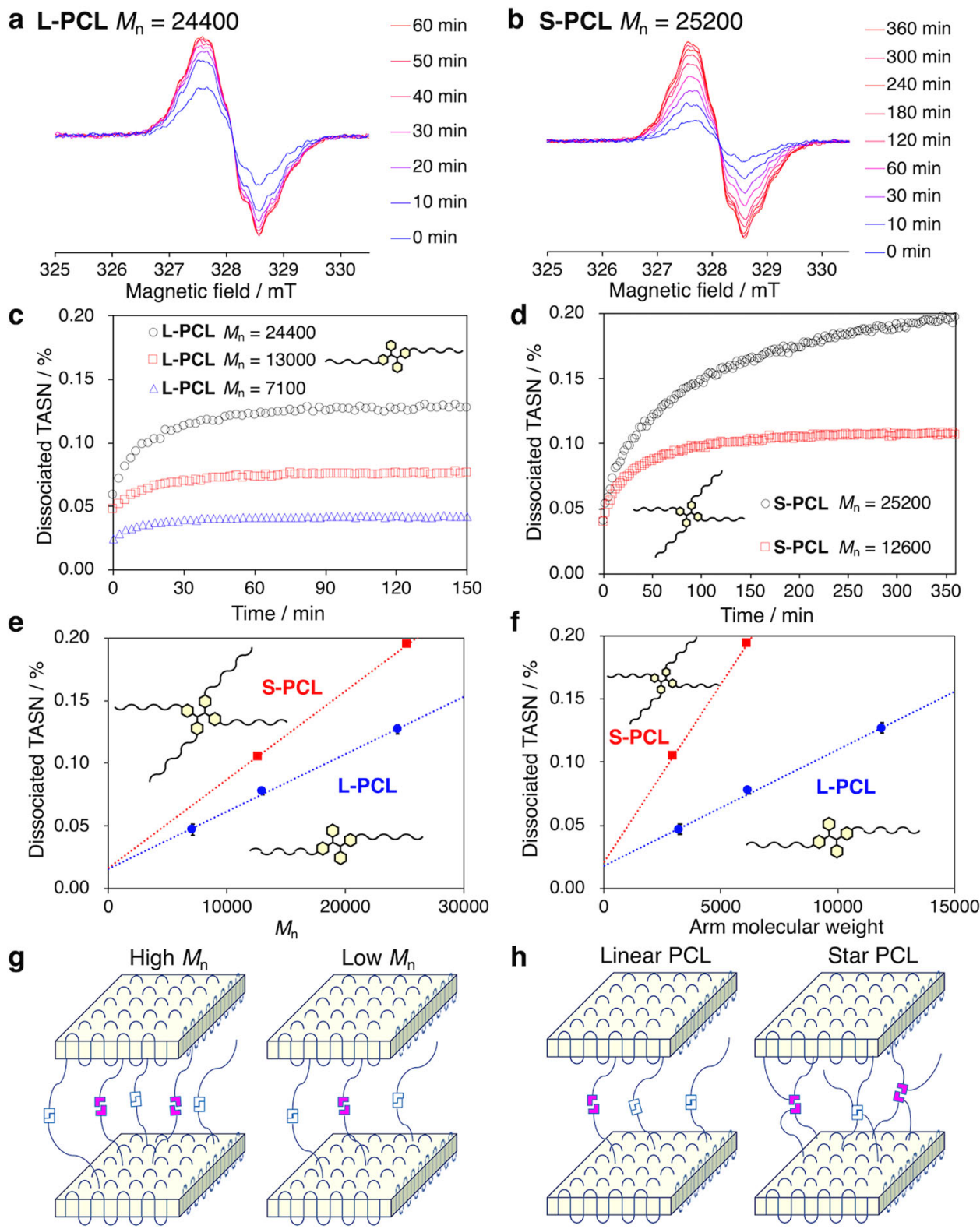

Fig. 3 Generation of radicals during isothermal crystallization. EPR spectra of $(\mathbf{a}) \mathbf{L}-\mathbf{P C L}\left(M_{n, N M R}=24400\right)$ and $(\mathbf{b}) \mathbf{S}-\mathbf{P C L}\left(M_{n, N M R}=25,200\right)$ during isothermal crystallization. Dissociated TASN (\%) in (c) L-PCL $\left(M_{n, N M R}=7100\right.$ : black circle, 13,000: red square, and 24,400: blue triangle) and (d) S-PCL $\left(M_{n, N M R}=12,600\right.$ : black circle, and 25,200: red square) during isothermal crystallization. e Relationship between molecular weight and dissociated TASN (\%) of L-PCL $\left(M_{n, N M R}=7100,13,000\right.$, and 24,400; blue circle and line $)$ and S-PCL $\left(M_{n, N M R}=12,600\right.$ and 25,200; red square and line) during isothermal crystallization. $\mathbf{f}$ Linear relationship between the molecular weight of the arm and dissociated TASN (\%) of L-PCL $\left(M_{n, N M R}=7100,13,000\right.$, and 24,400 ; blue circle and line) and S-PCL $\left(M_{n, N M R}=12,600\right.$ and 25,200; red square and line) during isothermal crystallization. Plausible schematic illustration of chain conformations of ( $\mathbf{g}$ ) high- and low-molecular-weight polymers and (h) linear and star-shaped crystalline polymers between lamellar structures.

Quantitative evaluation of the amount of radicals generated during CIMF. The generation of radicals during the isothermal crystallization was examined for the L-PCLs and S-PCLs. In the present system, the mechanical force induced by crystallization can be evaluated by EPR measurements of the generated radicals. We speculate that the knowledge of unpaired spin density may allow quantitative estimates of segmental forces by assuming that the dissociated radicals from TASN moieties can be detected without oxidation, which is controlled by the sealing of the capillary after being degassed. The concentration of the radicals formed from the cleavage of TASN was determined by comparing the area of the observed integral spectrum with a $0.01-\mathrm{mM}$ solution of 4-hydroxy-2,2,6,6-tetramethylpiperidin-1-oxyl (TEMPOL) in benzene under the same experimental conditions. The PCL samples were fully molten at $70^{\circ} \mathrm{C}$, and subsequently cooled to $30^{\circ} \mathrm{C}$ (cooling rate: $-20^{\circ} \mathrm{C} \mathrm{min}^{-1}$ ) for crystallization. Figure $3 \mathrm{a}, \mathrm{b}$ show the EPR spectra of L-PCL $\left(M_{\mathrm{n}}=24,400\right)$ and S-PCL $\left(M_{\mathrm{n}}=\right.$ $25,200)$, respectively, during the crystallization at $30^{\circ} \mathrm{C}$. The calculated $g$ value (2.003) in both cases indicates that the generated radicals are carbon-centered. The signal intensity generated from TASN increases with time. Fig. $3 \mathrm{c}$, d show the dissociation ratios of TASN calculated from the EPR spectra in Fig. 3a, b, respectively. The TASN dissociation ratio reached an equilibrium after 90 minutes for L-PCL and after $330 \mathrm{~min}$ for S-PCL. It should be noted that the time to reach the equilibrium approximately doubled when the molecular weight doubled ${ }^{38-41}$.

Figure $3 \mathrm{e}, \mathrm{f}$ show the plots of the dissociation ratios of the TASN moiety for the PCL samples as a function of the molecular 
weight and molecular weight of the arm, respectively. These data suggest (1) an increase in the dissociation ratio of the TASN moiety with increasing molecular weight and (2) a large difference in the dissociation ratio of the TASN moiety due to the difference in primary structures (linear or star-shaped polymers). A plausible mechanism to rationalize the experimentally observed results could be based on the following considerations: (1) with increasing molecular weight in the same crystallinity (Table 1), the fraction of TASN moieties between crystallites $^{6,7,42-44}$, and hence the fraction of 'active' TASN moieties, i.e., moieties dissociated in response to mechanical stress induced by crystallization would increase (Fig. 3g). (2) When comparing the topology between linear and star-shaped polymers that contain arms of identical molecular weight (Fig. 3f), S-PCL polymers have more arms involved in the formation of lamellar layers, which would lead to a further increase of 'active' TASN moieties that serve as tie molecules compared to L-PCL polymers (Fig. 3h). The mechano-activation behavior strongly depends on the environment of the mechanophore ${ }^{11}$. In solution under ultrasonication, single mechanophores at the center of the main chain are more likely to be activated in polymers with high molecular length ${ }^{45,46}$. On the other hand, in the bulk state under exposure to grinding, the mechano-responsiveness of mechanochromophores, especially radical-type mechanophores such as TASN, is governed by both the molecular weight and the number of branches ${ }^{47,48}$. The insights into mechano-responsiveness in polymer crystallization obtained in this paper are expected to broaden the understanding of polymer mechanochemistry.
Fluorescence microscopy measurements of CIMF. The visualization of the crystallization process, which is the most important part of this paper, was performed by confocal laser scanning microscopy (CLSM). So far, the twisting behavior of lamellar crystals in spherulites ${ }^{49-52}$ has been examined by polarized light microscopy ${ }^{38,53}$, small-angle light scattering 54 , transmission electron microscopy ${ }^{30}$, scanning electron microscopy ${ }^{55}$, and atomic force microscopy $29,56,57$. However, reports on the residual stress of the twisting behavior during the growth of spherulites remain elusive. Here, we addressed this dearth by converting the micro-mechanical forces during polymer crystallization into fluorescence arising from dissociated TASN radicals generated during the growth of the spherulites.

As shown in Fig. 4a (Supplementary Movie 1), microscopy images of L-PCL $\left(M_{\mathrm{n}}=24,400\right)$ recorded at $30^{\circ} \mathrm{C}$ reveal that spherulites grow from the molten state. Furthermore, a comparison with the bright-field images (Supplementary Fig. 22) demonstrated that the fluorescence emission is observed only in the growth direction of the lamellar crystals, while $\mathbf{C}_{\mathbf{1}}-\mathbf{P C L}$, which does not contain TASN moieties, exhibited no fluorescence (Fig. 4b). In contrast, $\mathbf{C}_{\mathbf{2}}$-PCL, which contains a fluorescein moiety, exhibited fluorescence in both the crystalline and the amorphous regions (Supplementary Fig. 27). As shown in Fig. 4c, the fluorescence intensity increased during isothermal crystallization with increasing crystallinity, which was estimated based on DSC measurements under identical thermal conditions. The strong relationship between the fluorescence intensity and the crystallinity indicates that the stress generated during the growth a

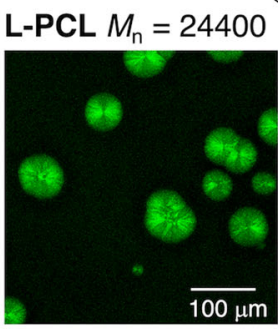

b

Os

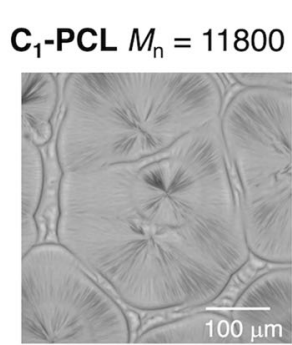

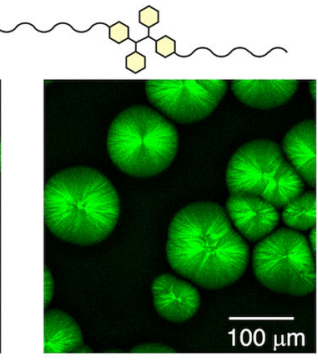

$50 \mathrm{~s}$

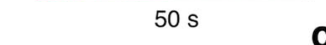

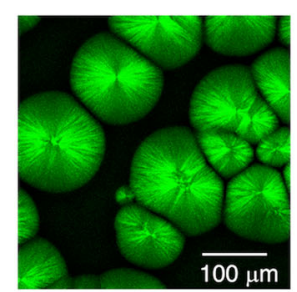
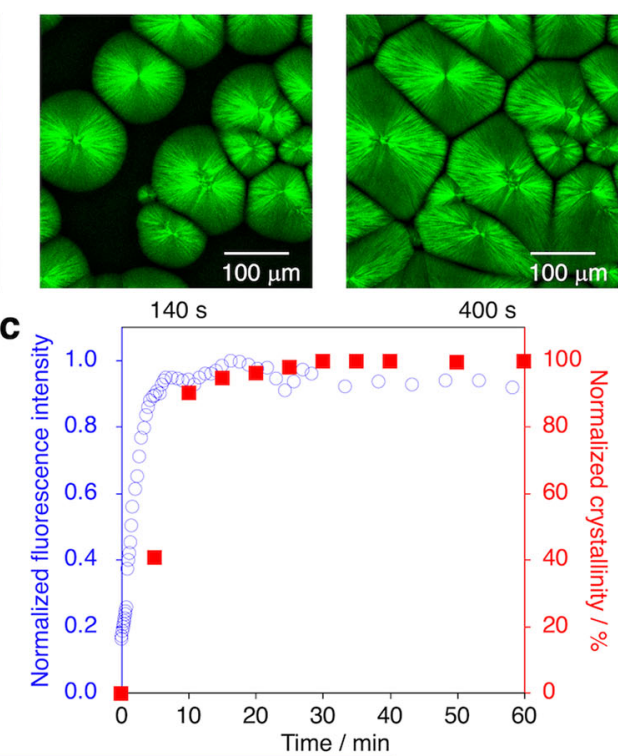

d
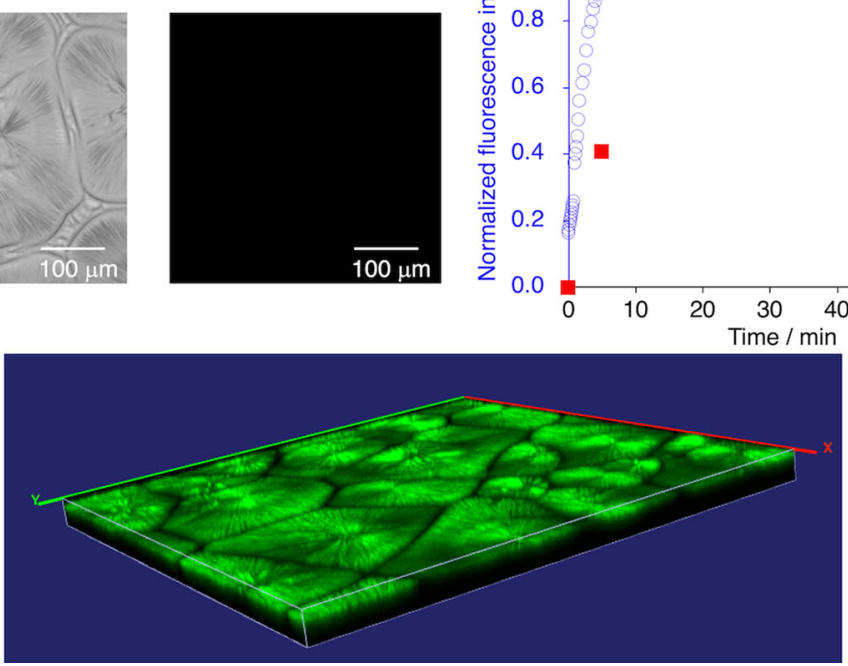

Fig. 4 Visualization of micro-mechanical forces during isothermal crystallization. a Microscopic images of $\mathbf{L}-\mathbf{P C L}\left(M_{\mathrm{n}}=24,400\right)$ captured by confocal laser scanning microscopy (CLSM; $\lambda_{\text {ex }}=514 \mathrm{~nm}$; scale bar: $\left.100 \mu \mathrm{m}\right)$ during isothermal crystallization. b Microscopic images of C-PCL $\left(M_{\mathrm{n}}=11,800\right)$ under bright-field conditions (left) and under excitation (right; $\lambda_{\mathrm{ex}}=514 \mathrm{~nm}$; scale bar: $100 \mu \mathrm{m}$ ) during isothermal crystallization. c Normalized fluorescence intensity (blue open circles) and normalized crystallinity (red closed squares) during isothermal crystallization for L-PCL $\left(M_{n}=24,400\right)$. $\mathbf{d} 3 D$ image of L-PCL $\left(M_{n}=24,400\right)$ alpha mode captured by $\operatorname{CLSM}\left(\lambda_{\mathrm{ex}}=514 \mathrm{~nm}\right.$; scale bar: $\left.100 \mu \mathrm{m}\right)$ after isothermal crystallization. 
of the spherulites can be evaluated at the molecular level. This tool could thus be used to evaluate micro-mechanical forces during polymer crystallization in the field of crystal growth, and also as a guideline for the molecular design of advanced materials.

We also confirmed that the distribution of the skewness and kurtosis in the fluorescence region (Supplementary Fig. 23) decreased with the growth of the lamellar crystals, which indicates that the spherulites are growing uniformly in two dimensions. CLSM also enables scanning the spherulites in 3D scan mode ${ }^{58}$ (Fig. 4d, Supplementary Figs. 25 and 26) as well as in airyscan mode (Supplementary Fig. 24), which allows detailed observations on the growth of lamellar crystals. It should be noted that the direct visualization of polymer crystallization with mechanoactivated fluorescent radicals offers unprecedented insight into crystal growth processes.

\section{Discussion}

Radical-type mechanofluorophores such as tetraarylsuccinonitrile (TASN) allow us to evaluate the micro-mechanical forces during polymer crystallization in crystalline polymers by electron paramagnetic resonance (EPR) spectroscopy and to visualize it by fluorescence microscopy. The radical-generating behavior and the real-time stress visualization have revealed the relationship between crystalline polymer architecture and the efficiency of the force transmission during the growth of spherulites. The increase of molecular weight of the main chain affects the dissociation of TASN at tie molecules, whereby star-shaped polycaprolactone contain more micro-mechanical forces during polymer crystallization at tie molecules than linear polycaprolactones. This strategy can be expected to be applicable to a wide variety of polymers in order to evaluate their micro-mechanical forces during polymer crystallization, which may ultimately lead to design guidelines for advanced materials. We are convinced that this report on crystallization-induced mechanofluorescence (CIMF) will open research avenues in polymer and materials sciences.

\section{Methods}

Preparation of polymers containing TASN moiety. The synthesis, purification, and characterization, which includes the NMR, IR, DSC and GPC data, mechanical characterization, control experiments, and additional details for all polymers, are described in detail in Supplementary Information.

\section{Evaluations of dissociated TASN radicals during polymer crystallization.} Variable-temperature EPR measurements were carried out on a JEOL JES-X320 Xband EPR spectrometer equipped with a JEOL DVT temperature controller. The samples were filled to $5 \mathrm{~mm}$ glass capillaries, and the capillaries were sealed after being degassed. In case of isothermal crystallization, the glass capillaries were heated to $70^{\circ} \mathrm{C}$ to melt the crystalline polymer absolutely, then the sample was kept at $30^{\circ} \mathrm{C}$ (cooling rate: $-20^{\circ} \mathrm{C} \mathrm{min}-1$ ) and measured. The spectra of samples were measured using microwave power of $0.1 \mathrm{~mW}$ and a field modulation of $0.1 \mathrm{mT}$ with a time constant of $0.03 \mathrm{~s}$ and a sweep rate of $0.25 \mathrm{mTs}^{-1}$. The concentration of the radicals formed from the cleavage of TASN was determined by comparing the area of the observed integral spectrum with a $0.01 \mathrm{mM}$ solution of 4-hydroxy2,2,6,6-tetramethylpiperidin-1-oxyl (TEMPOL) in benzene under the same experimental conditions. The $\mathrm{Mn}^{2+}$ signal was used as an auxiliary standard.

\section{CLSM experiments to observe crystallization-induced mechanofluorescence}

The expression of mechano-activated fluorescence from TASN moiety at the center of the main chain was visualized by a Zeiss LSM880 with Airyscan (Carl Zeiss, Oberkochen, Germany) with $\times 20$ objective lens using $514 \mathrm{~nm}$ excitation and 526-651 nm emission wavelengths for L-PCL, S-PCL, and $\mathbf{C}_{\mathbf{1}}-\mathbf{P C L}$. For isothermal crystallization, the samples placed on the cover glass $(18 \mathrm{~mm} \times 18 \mathrm{~mm})$ were heated to $70^{\circ} \mathrm{C}$, then the sample was kept at $30^{\circ} \mathrm{C}$. As a control sample, $\mathbf{C}_{2}-\mathrm{PCL}$ was visualized using $488 \mathrm{~nm}$ excitation and 506-647 emission wavelengths. All samples were prepared by spin coater MSC-200D (Japan Create Co., Ltd.). The spin coating conditions are as following; polymer concentration: $120 \mathrm{mg} / \mathrm{mL}$, rotational speed of disk: $800 \mathrm{rpm}, 30 \mathrm{~s}$, solvent: 1,2-dichloroethane.

\section{Data availability}

All data supporting the findings of this study are available within the article and its Supplementary Information. All other data are available from the corresponding author upon reasonable request.

Received: 29 May 2020; Accepted: 24 November 2020; Published online: 05 January 2021

\section{References}

1. Zhang, Y., Ben Jar, P. Y., Xue, S. \& Li, L. Quantification of strain-induced damage in semi-crystalline polymers: a review. J. Mater. Sci. 54, 62-82 (2018).

2. Bernhard, W. Macromolecular Physics. 1-3 (Academic Press, 1973).

3. Sanchez, L. A. \& Hornberger, L. E. Monitoring of residual stresses in injectionmolded plastics with holographic interferometry. Opt. Lasers Eng. 37, 27-37 (2002).

4. Maxwell, A. S. \& Turnbull, A. Measurement of residual stress in engineering plastics using the hole-drilling technique. Polym. Test. 22, 231-233 (2003).

5. Pittman, J. F. T., Whitham, G. P., Beech, S. \& Gwynn, D. Cooling and wall thickness uniformity in plastic pipe manufacture -an experimental study and computer simulations-. Int. Polym. Proc. 9, 130-140 (1994).

6. Seguela, R. Critical review of the molecular topology of semicrystalline polymers: the origin and assessment of intercrystalline tie molecules and chain entanglements. J. Polym. Sci. B Polym. Phys. 43, 1729-1748 (2005).

7. Huang, Y.-L. \& Brown, N. Dependence of slow crack growth in polyethylene on butyl branch density: morphology and theory. J. Polym. Sci. B Polym. Phys. 29, 129-137 (1991)

8. Gautam, S., Balijepalli, S. \& Rutledge, G. C. Molecular simulations of the interlamellar phase in polymers: effect of chain tilt. Macromolecules 33, 9136-9145 (2000).

9. Nilsson, F., Lan, X., Gkourmpis, T., Hedenqvist, M. S. \& Gedde, U. W. Modelling tie chains and trapped entanglements in polyethylene. Polymer 53, 3594-3601 (2012).

10. Beyer, M. K. \& Clausen-Schaumann, H. Mechanochemistry: the mechanical activation of covalent bonds. Chem. Rev. 105, 2921-2948 (2005).

11. Li, J., Nagamani, C. \& Moore, J. S. Polymer mechanochemistry: from destructive to productive. Acc. Chem. Res. 48, 2181-2190 (2015).

12. Izak-Nau, E., Campagna, D., Baumann, C. \& Göstl, R. Polymer mechanochemistry-enabled pericyclic reactions. Polym. Chem. 11, 2274-2299 (2020).

13. Min, Y. Q. et al. Sonochemical transformation of epoxy-amine thermoset into soluble and reusable polymers. Macromolecules 48, 316-322 (2015).

14. Piermattei, A., Karthikeyan, S. \& Sijbesma, R. P. Activating catalysts with mechanical force. Nat. Chem. 1, 133-137 (2009).

15. Zhang, $\mathrm{H}$. et al. Mechanochromism and mechanical-force-triggered crosslinking from a single reactive moiety incorporated into polymer chains. Angew. Chem. Int. Ed. 55, 3040-3044 (2016).

16. Chen, Z. et al. Mechanochemical unzipping of insulating polyladderene to semiconducting polyacetylene. Science 357, 475-479 (2017).

17. Davis, D. A. et al. Force-induced activation of covalent bonds in mechanoresponsive polymeric materials. Nature 459, 68-72 (2009).

18. Chen, Y. et al. Mechanically induced chemiluminescence from polymers incorporating a 1,2-dioxetane unit in the main chain. Nat. Chem. 4, 559-562 (2012).

19. Robb, M. J. et al. Regioisomer-specific mechanochromism of naphthopyran in polymeric materials. J. Am. Chem. Soc. 138, 12328-12331 (2016).

20. Larsen, M. B. \& Boydston, A. J. "Flex-activated" mechanophores: using polymer mechanochemistry to direct bond bending activation. J. Am. Chem. Soc. 135, 8189-8192 (2013).

21. Clough, J. M., van der Gucht, J. \& Sijbesma, R. P. Mechanoluminescent imaging of osmotic stress-induced damage in a glassy polymer network. Macromolecules 50, 2043-2053 (2017).

22. Imato, K. et al. Mechanophores with a reversible radical system and freezinginduced mechanochemistry in polymer solutions and gels. Angew. Chem. Int Ed. 54, 6168-6172 (2015).

23. Kato, S., Ishizuki, K., Aoki, D., Goseki, R. \& Otsuka, H. Freezing-induced mechanoluminescence of polymer gels. ACS Macro Lett. 7, 1087-1091 (2018)

24. Kato, S., Aoki, D. \& Otsuka, H. Introducing static cross-linking points into dynamic covalent polymer gels that display freezing-induced mechanofluorescence: enhanced force transmission efficiency and stability. Polym. Chem. 10, 2636-2640 (2019).

25. Verstraeten, F., Gostl, R. \& Sijbesma, R. P. Stress-induced colouration and crosslinking of polymeric materials by mechanochemical formation of triphenylimidazolyl radicals. Chem. Commun. 52, 8608-8611 (2016).

26. Sumi, T., Goseki, R. \& Otsuka, H. Tetraarylsuccinonitriles as mechanochromophores to generate highly stable luminescent carbon-centered radicals. Chem. Commun. 53, 11885-11888 (2017). 
27. Crescenzi, V., Manzini, G., Calzolari, G. \& Borri, C. Thermodynamics of fusion of poly- $\beta$-propiolactone and poly- $\epsilon$-caprolactone. comparative analysis of the melting of aliphatic polylactone and polyester chains. Eur. Polym. J. 8, 449-463 (1972).

28. Wang, Y., Rodriguez-Perez, M. A., Reis, R. L. \& Mano, J. F. Thermal and thermomechanical behaviour of polycaprolactone and starch/polycaprolactone blends for biomedical applications. Macromol. Mater. Eng. 290, 792-801 (2005).

29. Beekmans, L. G. M. \& Vancso, G. J. Real-time crystallization study of poly( $(\varepsilon-$ caprolactone) by hot-stage atomic force microscopy. Polymer 41, 8975-8981 (2000).

30. Ikehara, T., Jinnai, H., Kaneko, T., Nishioka, H. \& Nishi, T. Local lamellar structures in banded spherulites analyzed by three-dimensional electron tomography. J. Polym. Sci. B Polym. Phys. 45, 1122-1125 (2007).

31. Toda, A., Taguchi, K. \& Kajioka, H. Growth of banded spherulites of poly( $\varepsilon$ caprolactone) from the blends: an examination of the modeling of spherulitic growth. Polymer 53, 1765-1771 (2012).

32. Wang, K., Cai, L., Jesse, S. \& Wang, S. Poly( $\varepsilon$-caprolactone)-banded spherulites and interaction with MC3T3-E1 cells. Langmuir 28, 4382-4395 (2012).

33. Nojima, S., Ono, M. \& Ashida, T. Crystallization of block copolymers II. morphological study of poly (ethylene glycol)-Poly ( $\varepsilon$-caprolactone) block copolymers. Polym. J. 24, 1271-1280 (1992).

34. Nojima, S., Inokawa, D., Kawamura, T. \& Nitta, K. Dynamic mechanical study of block copolymer crystallization confined within spherical nanodomains. Polym. J. 40, 986-991 (2008).

35. Kossack, W. \& Kremer, F. Banded spherulites and twisting lamellae in polyE-caprolactone. Colloid Polym. Sci. 297, 771-779 (2019).

36. Makiguchi, K., Satoh, T. \& Kakuchi, T. Diphenyl phosphate as an efficient cationic organocatalyst for controlled/living ring-opening polymerization of $\delta$ valerolactone and $\varepsilon$-caprolactone. Macromolecules 44, 1999-2005 (2011).

37. Saito, T., Aizawa, Y., Tajima, K., Isono, T. \& Satoh, T. Organophosphatecatalyzed bulk ring-opening polymerization as an environmentally benign route leading to block copolyesters, end-functionalized polyesters, and polyester-based polyurethane. Polym. Chem. 6, 4374-4384 (2015).

38. Hoffman, J. D. \& Miller, R. L. Test of the reptation concept: crystal growth rate as a function of molecular weight in polyethylene crystallized from the melt. Macromolecules 21, 3038-3051 (1988).

39. Abe, H., Kikkawa, Y., Inoue, Y. \& Doi, Y. Morphological and kinetic analyses of regime transition for poly[(S)-lactide] crystal growth. Biomacromolecules 2, 1007-1014 (2001).

40. Tsuji, H., Tezuka, Y., Saha, S. K., Suzuki, M. \& Itsuno, S. Spherulite growth of 1-lactide copolymers: effects of tacticity and comonomers. Polymer 46, 4917-4927 (2005).

41. Jancar, J. \& Fiore, K. Molecular weight scaling of the spherulite growth rate in isothermally melt crystallized polyethylene nanocomposites. Polymer 52, 5851-5857 (2011).

42. Phillips, P. J. \& Rensch, G. J. Crystallization studies of poly( $\varepsilon$-caprolactone). II. Lamellar thickening melting.J. Polym. Sci. B Polym. Phys. 27, 155-173 (1989).

43. Adhikari, S. \& Muthukumar, M. Theory of statistics of ties, loops, and tails in semicrystalline polymers. J. Chem. Phys. 151, 114905 (2019).

44. Zhai, Z., Morthomas, J., Fusco, C., Perez, M. \& Lame, O. Crystallization and molecular topology of linear semicrystalline polymers: simulation of uni- and bimodal molecular weight distribution systems. Macromolecules $\mathbf{5 2}$ 4196-4208 (2019).

45. Church, D. C., Peterson, G. I. \& Boydston, A. J. Comparison of mechanochemical chain scission rates for linear versus three-arm star polymers in strong acoustic fields. ACS Macro Lett. 3, 648-651 (2014).

46. May, P. A., Munaretto, N. F., Hamoy, M. B., Robb, M. J. \& Moore, J. S. Is Molecular weight or degree of polymerization a better descriptor of ultrasound-induced mechanochemical transduction? ACS Macro Lett. 5, 177-180 (2016).

47. Oka, H. et al. Enhancing mechanochemical activation in the bulk state by designing polymer architectures. ACS Macro Lett. 5, 1124-1127 (2016)

48. Watabe, T., Ishizuki, K., Aoki, D. \& Otsuka, H. Mechanochromic dendrimers: the relationship between primary structure and mechanochromic properties in the bulk. Chem. Commun. 55, 6831-6834 (2019).

49. Crist, B. \& Schultz, J. M. Polymer spherulites: a critical review. Prog. Polym Sci. 56, 1-63 (2016).

50. Shtukenberg, A. G., Punin, Y. O., Gujral, A. \& Kahr, B. Growth actuated bending and twisting of single crystals. Angew. Chem. Int. Ed. 53, 672-699 (2014).
51. Lovinger, A. J. Twisted crystals and the origin of banding in spherulites of semicrystalline polymers. Macromolecules 53, 741-745 (2020)

52. Woo, E. M., Lugito, G. \& Nagarajan, S. Dendritic polymer spherulites: birefringence correlating with lamellae assembly and origins of superimposed ring bands. J. Polym. Res. 27, 7 (2019).

53. Ye, L., Qiu, J., Wu, T., Shi, X. \& Li, Y. Banded spherulite templated threedimensional interpenetrated nanoporous materials. RSC Adv. 4, 43351-43356 (2014).

54. Baert, J. \& Van Puyvelde, P. Density fluctuations during the early stages of polymer crystallization: an overview. Macromol. Mater. Eng. 293, 255-273 (2008).

55. Wang, Z. et al. Twisting of lamellar crystals in poly(3-hydroxybutyrate-co-3hydroxyvalerate) ring-banded spherulites. Macromolecules 43, 4441-4444 (2010).

56. Jiang, Y. et al. Lamellar branching of poly(bisphenol A-co-decane) spherulites at different temperatures studied by high-temperature AFM. Macromolecules 36, 3652-3655 (2003)

57. Mareau, V. H. \& Prud'homme, R. E. In-situ hot stage atomic force microscopy study of poly( $\varepsilon$-caprolactone) crystal growth in ultrathin films. Macromolecules 38, 398-408 (2005).

58. Peng, H., Ruan, Z., Long, F., Simpson, J. H. \& Myers, E. W. V3D enables realtime $3 \mathrm{D}$ visualization and quantitative analysis of large-scale biological image data sets. Nat. Biotechnol. 28, 348-353 (2010).

\section{Acknowledgements}

This work was supported by KAKENHI grants 17H01205 (H.O.) from the Japan Society for the Promotion of Science (JSPS), JSPS Research Fellowships for Young Scientists 19J23009 (S.K.), JST CREST (grant number JPMJCR1991, H.O.), and JST ERATO (grant number JPMJER1602, K.N).

\section{Author contributions}

S.K., S.F., D.A., R.G., and H.O. conceived the concept, designed the experiments. S.K. and S.F. performed the experiments and analyzed the data. S.K., S.F., D.A., R.G., K.O., K.T., N.S., A.M., K.N., and H.O. wrote the manuscript.

\section{Competing interests}

The authors declare no competing interests.

\section{Additional information}

Supplementary information is available for this paper at https://doi.org/10.1038/s41467020-20366-y.

Correspondence and requests for materials should be addressed to H.O.

Peer review information Nature Communications thanks the anonymous reviewers for their contribution to the peer review of this work.

Reprints and permission information is available at http://www.nature.com/reprints

Publisher's note Springer Nature remains neutral with regard to jurisdictional claims in published maps and institutional affiliations.

pen Access This article is licensed under a Creative Commons Attribution 4.0 International License, which permits use, sharing, adaptation, distribution and reproduction in any medium or format, as long as you give appropriate credit to the original author(s) and the source, provide a link to the Creative Commons license, and indicate if changes were made. The images or other third party material in this article are included in the article's Creative Commons license, unless indicated otherwise in a credit line to the material. If material is not included in the article's Creative Commons license and your intended use is not permitted by statutory regulation or exceeds the permitted use, you will need to obtain permission directly from the copyright holder. To view a copy of this license, visit http://creativecommons.org/ licenses/by/4.0/.

(c) The Author(s) 2021 